\title{
Artigo Original / Original Paper \\ O vigor da planta altera a densidade de galhas em populações de Baccharis longiattenuata (Asteraceae) sob distintas condições de solo?
}

\author{
Maiara Matilde-Silva ${ }^{1,2}$, Maria Regina Torres Boeger ${ }^{1} \&$ João Carlos Ferreira de Melo Júnior ${ }^{2,3}$
}

\begin{abstract}
Resumo
A hipótese do vigor da planta sugere que plantas mais vigorosas suportam maior densidade de galhas. Este estudo avaliou tal hipótese utilizando o sistema ácaro-Baccharis longiattenuata em duas populações de restinga sob condições ambientais distintas. As medidas de vigor incluíram: altura e diâmetro do caule, volume e área da copa, número de folhas por ramo, teor de nitrogênio e área específica foliar. Os resultados evidenciaram o efeito do vigor sobre a densidade de galhas. Além do vigor da planta, outros fatores podem ter influenciado indiretamente no padrão observado. O maior aporte hídrico em restinga arbustivo-arbórea pode influenciar nas taxas de crescimento e formação de sítios meristemáticos, alterando a dinâmica galhador-hospedeiro. Diferente do esperado pela literatura, a população com folhas menos esclerófilas apresentou maior densidade de galhas. Por outro lado, em restinga arbustiva, os menores valores de $\mathrm{AEF}$, em resposta à alta incidência luminosa e menor disponibilidade hídrica no solo, podem ter influenciado a maior densidade de ácaros por galha. Folhas mais esclerófilas e longevas favorecem o tempo de permanência de fêmeas na galha, aumentando a densidade de ácaros por galha neste ambiente. É apresentada uma discussão sobre as condições ambientais que podem moldar o padrão de distribuição das galhas encontrado.

Palavras-chave: dinâmica galhador-planta hospedeira, galha de ácaros, herbivoria em restinga, hipótese do vigor, qualidade edáfica.
\end{abstract}

\begin{abstract}
The plant vigor hypothesis suggests that more vigorous plants support higher density of galls. This study will evaluate such hypothesis using a mite-Baccharis longiattenuata system in two restinga populations under different environmental conditions. The measures of vigor are: height and stem diameter, volume and crown area, number of leaves per branch, nitrogen content and specific leaf area. The results evidenced the vigor effect on the density of galls. In addition to plant vigor, other factors may have indirectly influenced the observed pattern. In shrub-tree restinga, the highest water intake may have influenced the growth rates and formation of meristematic sites, which changes the gall-host dynamics. Different than expected in the literature, a population with less sclerophyllous leaves presented higher density of galls. On the other hand, in shrub restinga, the lowest SLA values, in response to high light incidence and lower soil water availability, may be influenced by higher density of mites per gall, since more sclerophyllous leaves have greater longevity, favoring in the time of permanence of the mature female inside the gall, increasing the density of mites per gall in this environment. A discussion is presented of environmental conditions that conform to the gall distribution pattern found.
\end{abstract}

Key words: gall-host dynamics, mite gall, herbivory in restinga, vigor hypothesis, edaphic quality.

\section{Introdução}

Galhas são estruturas induzidas em plantas por uma diversidade de organismos, tais como insetos, fungos, bactérias, nematódeos ou ácaros e consiste em uma interação altamente espécie- específica (Price et al. 1987). As galhas são resultantes de alterações em células meristemáticas de diversos órgãos vegetais, e, dentro destas estruturas o galhador propaga sua prole (Mani 1964; Espírito-Santo et al. 2007; Oliveira et

\footnotetext{
${ }^{1}$ Universidade Federal do Paraná, Prog. Pós-graduação em Ecologia e Conservação, C.P. 19031, 81531-990, Curitiba, PR, Brasil.

${ }^{2}$ Universidade da Região de Joinville, Depto. Ciências Biológicas, Lab. Anatomia e Ecologia Vegetal, R. Paulo Maschitzki 10, 89219-710, Joinville, SC, Brasil.

${ }^{3}$ Autor para correspondência: jcmelo_wood@hotmail.com
} 
al. 2016), providenciando um local protegido das condições ambientais extremas, como altas temperaturas e baixa umidade do ar, dos inimigos naturais, além de proporcionar alimento disponível para o desenvolvimento de um estágio de vida da prole, ou mesmo de toda vida e futuras gerações, como é o caso dos ácaros (Mani 1964; Price et al. 1987).

Os ácaros galhadores pertencem à família Eriophyidae (Keifer et al. 1982) e são relativamente bem conhecidos, uma vez que são considerados pragas agrícolas devido à alta taxa de reprodução e ampla propagação e dano sobre espécies de importância comercial (Moraes \& Flechtmann 1981; Guedes et al. 2007; Damasceno 2008).

A densidade de galhas sobre seus hospedeiros, bem como as taxas de desenvolvimento dos galhadores dependem de um conjunto de fatores, tais como aspectos físicos e populacionais da planta hospedeira, além da qualidade ambiental onde os hospedeiros ocorrem (White 1969; Price 1991; Espírito-Santo et al. 2007; Moura et al. 2009; Nasareen \& Ramani 2015; Price \& Hunter 2015).

Diversas hipóteses foram formuladas com o intuito de explicar quais são os fatores que alteram a dinâmica galhador-hospedeiro, dentre elas a hipótese do vigor da planta (HVP) (Price 1991). Segundo esta hipótese, hospedeiros mais vigorosos suportam um maior número de galhadores, uma vez que apresentam maior aparência, maior oferta de recurso alimentar, mais sítios de oviposição e maior número de folhas novas com tecido ainda reativo para a indução de galhas. O vigor da planta refere-se ao seu crescimento total ou dos módulos que compõem o seu corpo (Price 1991).

É sabido que em ambientes xéricos, ocorre uma alta diversidade e abundância de galhas (Fernandes \& Price 1992; Price 1987), por isso, uma gama de estudos tem sido conduzida em vegetações sob condições xéricas, como cerrados, restingas e dosséis de florestas, com a finalidade de identificar as dinâmicas galhador-hospedeiro (Ribeiro \& Basset 2007; Tuller et al. 2013; Julião et al. 2014; Arriola et al. 2015; Arriola \& Melo Jr. 2016; Silva et al. 2016).

Avaliando a relação entre vigor e abundância de galhas em plantas de cerrado, Gonçalves-Alvim et al. (1999) identificaram padrões diferenciados para cada espécie de galhador, sendo que duas espécies apresentaram correlação positiva e negativa com o vigor do ramo e as outras duas espécies não apresentam correlação com o vigor do ramo. Almeida et al. (2008) evidenciaram uma dinâmica semelhante, onde a densidade de galhas sobre Astronium fraxinifolium (Anacardiaceae) não tem correlação com o vigor da planta. Por outro lado, os autores argumentaram que a idade da folha, que é relacionada com a qualidade nutricional, pode apresentar maior influência sobre a abundância dos galhadores. Opondo-se aos resultados supracitados, Tuller et al. (2013) identificou uma correlação positiva entre comprimento do ramo e a abundância de galhas devido principalmente ao maior número de meristemas e, consequentemente, folhas novas e nutritivas, corroborando Mendonça (2009) e Fagundes \& Gonçalves (2005), os quais identificaram correlações positiva entre abundância de galhas e vigor.

Em restinga, a maioria dos estudos sobre galhas consistem em levantamento e registro de espécies (Bregonci et al. 2010; Maia 2013; Arriola et al. 2015; Arriola \& Melo Jr. 2016), sendo que poucos estudos avaliaram os fatores que afetam a dinâmica galha-hospedeiro. Em Dalbergia ecastophyllum (L.) Taubert. (Fabaceae), a densidade de galhas não apresentou correlação com o vigor da planta (Oliveira \& Cortez 2015). Entretanto, uma meta-análise demonstrou que $65 \%$ dos estudos identificaram um efeito positivo do vigor sobre a densidade de galhas (Cornelissen et al. 2008).

Restinga é o termo empregado para designar a comunidade vegetal que se desenvolve sobre sedimento arenoso ao longo da planície costeira. Devido à proximidade com a costa, a restinga recebe altos teores de sódio e a topologia é constantemente alterada pela ação eólica e das marés, o que torna este ambiente estressante (Scarano 2002). A estrutura e organização da comunidade vegetal, neste ambiente, são regidas principalmente pela qualidade edáfica, que aumenta no sentido mar-continente, devido ao aumento no teor de matéria orgânica e água disponíveis no solo (Melo Jr. \& Boeger 2015).

Considerando a hipótese do vigor e as características do ambiente de restinga, as perguntas a serem respondidas por este estudo são: i) há diferença no vigor da planta entre as populações de restinga arbustiva e arbustivoarbórea de restinga?; ii) há diferença na densidade de galhas entre as populações de Baccharis longiattenuata?; iii) se sim, o vigor é o "driver" determinante dos padrões encontrados como sugere a HVP?; iv) a maior densidade de ácaros ocorre na população de $B$. longiattenuata que abriga a maior densidade de galhas? As predições são que plantas 
de restinga arbustivo-arbórea são mais vigorosas, apresentam maior densidade de galhas e ácaros dentro das galhas e que tal padrão é influenciado pelo vigor das plantas.

\section{Material e Métodos}

\section{Local de estudo}

$O$ estudo foi realizado na restinga do Parque Estadual Acaraí (PEA), uma Unidade de Conservação de Preservação Integral localizada na Praia Grande, município de São Francisco do Sul, litoral norte de Santa Catarina, Brasil $\left(26^{\circ} 17^{\prime} \mathrm{S}\right.$ e $\left.48^{\circ} 33^{\prime} \mathrm{W}\right)$. Trata-se da maior restinga em extensão no estado, com cobertura vegetal de aproximadamente 6,7 ha. (FATMA 2008). A restinga do PEA é caracterizada por quatro principais formações vegetais: restinga herbácea (Rh) em neossolo quartzarênico, restingas arbustiva (Ra) e arbustivo-arbórea (Raa) em espodossolo ferrihumilúvico de natureza não hidromórfica e floresta de transição ( $\mathrm{Ft}$ ) em espodossolo ferrihumilúvico + organossolo háplico de natureza hidromórfica. Essas comunidades são regidas principalmente pela variação na disponibilidade de água e de nutrientes no solo que aumentam gradualmente no sentido mar-interior do continente (Melo Jr. \& Boeger 2015). O presente estudo foi desenvolvido nas formações de Ra e Raa.

\section{Espécie em estudo e coleta do material vegetal}

Para investigar a validade das predições da HVP, a espécie Baccharis longiattenuata A.S. Oliveira (Asteraceae) foi selecionada em ambiente de restinga por duas principais razões: 1) apresenta uma interação com um ácaro galhador, ainda não registrada na literatura e 2) está distribuída em restingas arbustiva e arbustivo-arbórea em um gradiente de aumento de fertilidade no solo.

Baccharis longiattenuata é uma espécie arbustiva nativa pertencente à família Asteraceae e apresenta distribuição na floresta ciliar, floresta estacional semidecidual e restingas do Rio Grande do Sul e Santa Catarina (Heiden \& Schneider 2015).

Por ser uma espécie pouco abundante nessa restinga (Melo Jr. \& Boeger 2015), foram utilizados dez indivíduos por formação vegetal para o estudo, assumindo que estes indivíduos são representativos das populações. Os critérios de inclusão dos indivíduos para o estudo foram: diâmetro a altura do peito (DAP) e diâmetro basal $\geq 3,5 \mathrm{~cm}$ para restinga arbustiva e distância mínima de $5 \mathrm{~m}$ entre os indivíduos amostrais. Durante a primavera de 2016 observações para identificar o período de desenvolvimento das galhas e marcações dos indivíduos foram realizadas. A coleta padronizada de todo o material vegetal ocorreu no período de um dia. Em campo, a altura e o diâmetro do caule de cada indivíduo amostral foram mensurados com auxílio de fita métrica. Foram calculados: o volume da planta, utilizando a fórmula do volume do cone $\left(\mathrm{V}=\left[\left(\pi \cdot r^{2} \cdot h\right) / 3\right]\right)$; e a área da copa, calculada a partir da fórmula: $\mathrm{A}=(\pi . \mathrm{a} . \mathrm{b})$, sendo "a" a maior largura da copa da planta e "b" a menor largura (Costa et al. 2010).

Foram coletados dez ramos da copa externa de cada indivíduo amostral. Cada ramo foi medido com régua milimetrada para posteriormente contagem do número de folhas apicais (nos primeiros $3 \mathrm{~cm}$ do ramo no sentido ápice-base) (Gonçalves-Alvim et al. 1999); número total de folhas; o número de folhas com galhas para avaliar a proporção de folhas parasitadas. O número de galhas por folha foi contabilizado para estimar a densidade de galhas por população de $B$. longiattenuata. $\mathrm{O}$ número de galhas por ramo foi dividido pelo número de folhas apicais para retirar o efeito da maior disponibilidade de recursos (Faria \& Fernandes 2001).

Vigor da planta

Os atributos de crescimento geral da planta (altura, DAP, volume da planta, área da copa e AEF) (Williams \& Cronin 2004), o crescimento modular (representado pelo comprimento médio dos ramos e por produção de folhas apicais) (Gonçalves-Alvim et al. 1999) e a qualidade nutricional das folhas (teor de nitrogênio e AEF) foram definidos como parâmetros de caracterização do vigor da planta (Price 1991).

\section{Análise do material vegetal}

Dez folhas sadias de cada ramo foram desidratadas em estufa a $60{ }^{\circ} \mathrm{C}$ até obter massa constante. A massa seca foliar ( $\mathrm{g}$ ) foi estimada em balança analítica de precisão e a área foliar $\left(\mathrm{cm}^{2}\right)$ foi calculada a partir de imagem digitalizada em scanner de mesa e tratada pelo Software Sigma Pro 5.0 (versão 5.0, SPSS Inc., Chicago IL, USA). A Área Específica Foliar (AEF) foi calculada (área foliar/massa seca foliar, $\mathrm{cm}^{2} \cdot \mathrm{g}^{-1}$ ) para estimar o investimento da planta em biomassa. A área foliar ocupada por galhas foi estimada através da subtração da área foliar total restante pela área foliar total. Para tanto, 20 folhas galhadas por indivíduo, secas em estufa a $60^{\circ} \mathrm{C}$ até obter massa 
constante, tiveram sua área medida utilizando imagem digitalizada em scanner de mesa, conforme procedimento citado acima, e posteriormente as galhas foram retiradas utilizando lâmina de bisturi para a mensuração da área foliar restante por meio do mesmo procedimento.

Para a qualidade nutricional do tecido vegetal o teor de nitrogênio foliar foi quantificado. Folhas sadias de cinco indivíduos por formação de restinga foram desidratadas a $30^{\circ} \mathrm{C}$, moídas em moinho tipo Bola (Oberstein, Fritsch Germany) e peneiradas em peneira com malha de $0,25 \mathrm{~mm}$. Cápsulas de 20 mg deste material foram montadas para análise de teor de nitrogênio em Analisador de Tecido Vegetal (Vario El III, Elementar) pelo método de combustão (Nelson \& Sommers 1996) no Laboratório de Solos e Engenharia Agrícola da UFPR, Curitiba, Paraná.

A dimensão das galhas foi obtida com auxílio de paquímetro digital a partir de 50 galhas (cinco galhas de cinco diferentes folhas por indivíduo) previamente fixadas em FAA e preservadas, após 48h, em álcool 70\% (Kraus \& Arduin 1997). A contagem do número de ácaros por galha, obtido em microscopia estereoscópica, foi precedida da sua remoção do interior das galhas com auxílio de agulha de $0,3 \times 5 \mathrm{~mm}$ após secagem transversal de 50 galhas coladas em lâmina de vidro com fita dupla face.

A descrição morfológica das galhas foi baseada na proposta de padronização de morfotipos de galhas para o Brasil (Isaias et al. 2013). Micrografias dos ácaros foram obtidas a partir de galhas recém coletadas. O material vegetal foi desidratado em série crescente de etanol e seco a ponto crítico com $\mathrm{CO} 2$ utilizando ponto crítico Bal-Tec, CPD030. As amostras foram montadas em "stubs" e metalizadas em vácuo com uma película de ouro usando Sputter Bal-Tec, SCD050. Observações e micrografias foram realizadas em Microscópio Eletrônico de Varredura Tescan Vega3 LMU do Centro de Microscopia da Universidade do Estado de Santa Catarina, UDESC.

\section{Análise dos componentes químicos}

do solo e da radiação

fotossinteticamente ativa

Dez amostras de solo foram coletadas nas restingas arbustiva e arbustivo-arbórea à uma profundidade de $15 \mathrm{~cm}$ e próximas aos indivíduos amostrais. Em laboratório, metade do solo de cada amostra foi pesada em balança analítica de precisão e, após 72 horas de secagem em estufa a $105^{\circ} \mathrm{C}$, foi novamente pesada para obter o conteúdo de água no solo pelo método da umidade gravimétrica
(EMBRAPA 2013). As metades restantes das amostras foram homogeneizadas, formando uma amostra composta para cada local, as quais foram destinadas à avaliação química, no Laboratório de Análise Química de Solo da EPAGRI/SC, por meio das variáveis de $\mathrm{pH}$, fósforo $(\mathrm{P})$, potássio $(\mathrm{K})$, sódio $(\mathrm{Na})$, magnésio $(\mathrm{Mg})$, acidez potencial $\left(\mathrm{H}+\mathrm{Al}\right.$, íons $\left.\mathrm{H}+\mathrm{e} \mathrm{Al}{ }^{3+}\right)$, soma de bases (SB), capacidade de troca catiônica (CTC), saturação por bases (V) e matéria orgânica (MO) de acordo com o método descrito por Tedesco et al. (1995). Dez medidas de espessura da serapilheira foram tomadas com régua milimetrada na proximidade de cada indivíduo amostral.

A radiação fotossinteticamente ativa (PAR) foi estimada 10 vezes sobre cada indivíduo amostral $(\mathrm{n}=100)$, entre as 11:00 e 13:00 hr (horário local), devido à maior intensidade da radiação solar neste horário, utilizando um "light meter" (LI-250A, LICOR, Nebraska, USA).

\section{Análise estatística}

Para todos os atributos quantitativos, as médias e os desvios-padrão foram calculados, seguidos do teste de normalidade e normalidade dos resíduos. As médias de altura e volume da planta, DAP, área da copa, comprimento dos ramos, número de folhas apicais, número de folhas apicais com galhas, número total de folhas no ramo, número de folhas com galhas, porcentagem de folhas com galhas, peso seco foliar, área foliar, área específica foliar (AEF), área foliar com galha, número absoluto de galhas por folha, número de galhas/número de folhas apicais, área da galha, número de ácaros por galha e teor de nitrogênio foliar foram comparadas por Test $t \mathrm{de}$ Student afim de verificar se ocorre diferença nos atributos de vigor, densidade de galhas e densidade populacional de ácaros entre as populações de $B$. longiattenuata. A relação entre a densidade de galhas e o vigor da planta foi testada através de regressão linear simples (Borcard et al. 2011). Foram realizadas correlações de Pearson entre os atributos, para identificar covariação entre elas. Todas as análises estatísticas foram realizadas em R (versão 3.1.2) utilizando o pacote $\operatorname{Rcmdr}(2,1-7)$ e pacotes complementares (Crawley 2007).

\section{Resultados}

Maior vigor foi observado em plantas da restinga arbustivo-arbórea, representado pelos atributos de altura, DAP, área da copa, volume da planta e comprimento do ramo. Os indivíduos 
de restinga arbustiva apresentaram menor valor de área foliar, maior valor de peso seco e, consequentemente, menor AEF (Tab. 1). O número de folhas apicais não variou entre as populações (Tab. 1). O teor de nitrogênio foi alto em ambas as populações de $B$. longiattenuata, com maior teor em restinga arbustiva-arbórea (Tab. 1). A análise de regressão linear simples evidenciou que os atributos de teor de nitrogênio, área da copa e quantidade de folhas apicais apresentaram uma fraca relação de causa e efeito com a densidade de galhas nas populações de $B$. longiattenuata de restinga $\left(F,{ }_{1,998}=7,055, \mathrm{R}^{2}=0,006, \mathrm{p}<0,05 ; \mathrm{F},{ }_{1,998}=\right.$ $10,75, \mathrm{R}^{2}=0,009, \mathrm{p}<0,05 ; \mathrm{F},{ }_{1,998}=5,756, \mathrm{R}^{2}=0,004$, $\mathrm{p}<0,05$, respectivamente) (Fig. 1a-c). A diferença na densidade de ácaros é observada mesmo após retirar o efeito da quantidade de recurso (número de galha divido pelo número de folhas), conforme sugerido por Faria \& Fernandes (2001).

O número total médio de folhas por ramo e a densidade de galhas foram maiores em restinga arbustiva-arbórea (Tab. 1). O tamanho das galhas foi similar entre as populações de B. longiattenuata, mas a densidade de ácaros dentro das galhas foi maior em restinga arbustiva (Tab. 1).
Os testes de correlação de Pearson demonstraram que a densidade de galhas apresenta correlação positiva com a AEF $(r=0,11, p<0,05)$, negativa com o teor de nitrogênio $(\mathrm{r}=-0.08$, $r<0,05)$, mas com o coeficiente de correlação baixas. Uma correlação positiva foi observada entre número de ácaros e área da galha $(\mathrm{r}=0.51$, $\mathrm{p}<0.05)$.

As galhas induzidas por ácaros (Acari: Eriophyidae) em Baccharis longiattenuata são globóides, glabras, de coloração vermelha nos estágios iniciais do desenvolvimento (Fig. 2a-b) e verde no estágio maduro (Fig. 2c-d), uniloculares (Fig. 2e-f) e abrigam em seu interior, em média, 85 ácaros em diferentes estágios de desenvolvimento, incluindo ovos, juvenis e adultos (Fig. 2f-h). Ocorrem de forma isolada ou agrupada por toda a superfície adaxial foliar (Fig. 2c-e). A galha se abre na superfície por meio de um orifício para a migração dos ácaros (Fig. 2d). As galhas desocupadas senescem, resultando em uma lesão na folha (Fig. 2d).

Os solos das formações de restinga estudadas são caracterizados como distróficos em função dos baixos valores da capacidade de troca catiônica
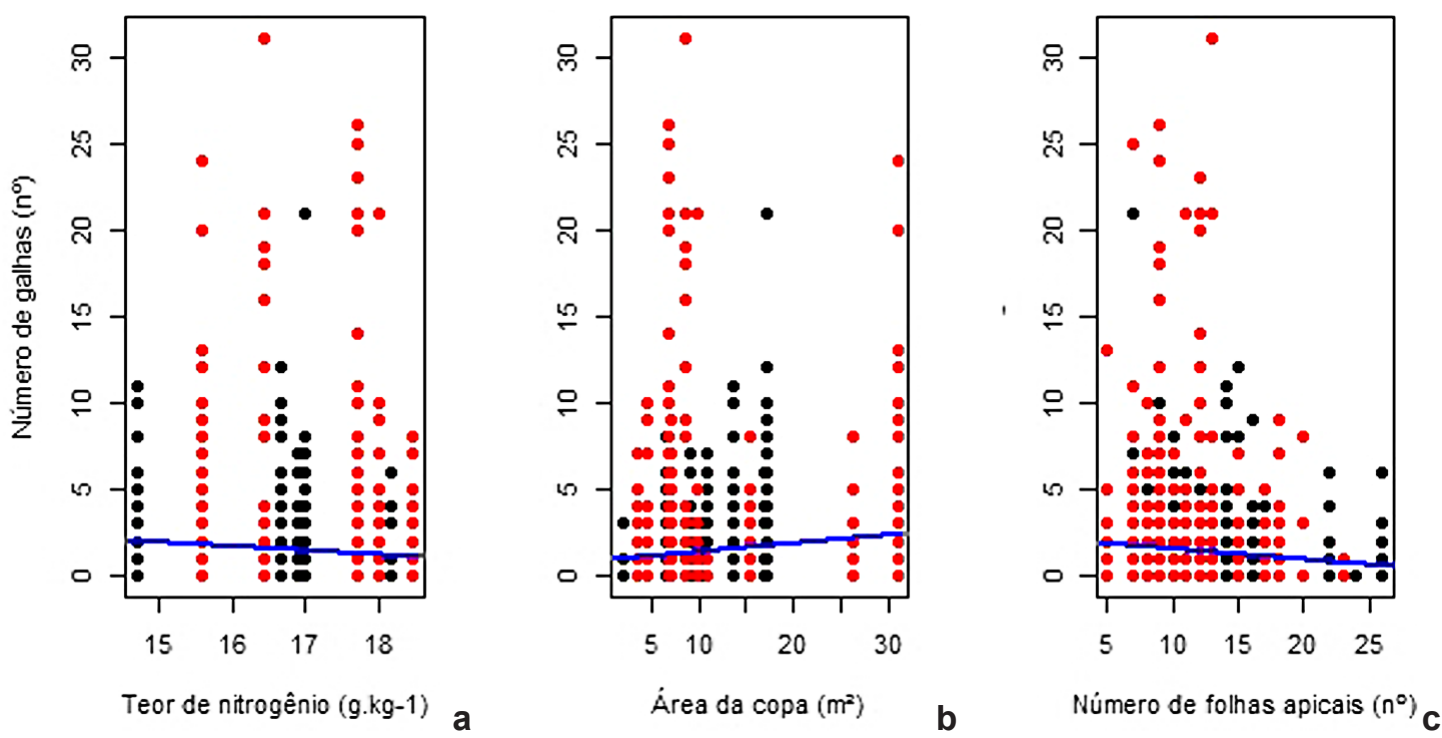

Figura 1 - Relação entre a densidade de galhas por ácaros e: a. nitrogênio foliar; b. área da copa; c. número de folhas apicais de indivíduos de Baccharis longiattenuata em restingas arbustiva (pontos pretos) e arbustiva-arbórea (pontos vermelhos) do Parque Estadual Acaraí, são Francisco do Sul, SC. As equações das retas são: a. y= 5.652-0.246x; b. $\mathrm{y}=0.920+0.047 \mathrm{x}$; c. $\mathrm{y}=2.213-0.062 \mathrm{x}$.

Figure 1 - Relationship between the density of galls by mites and: a. leaf nitrogen; b. crown area; c. number of apical leaves of Baccharis longiattenuata in shrub (black points) and shrub-tree areas (red points) restinga of the Parque Estadual do Acaraí, São Francisco do Sul, SC. The equations of regression lines are: $a . y=5.652-0.246 x ; b$. $y=0.920+0.047 x ; c$. $y=2.213-0.062 x$. 
Tabela 1 - Médias e respectivos desvios-padrão $( \pm)$ das características foliares e de crescimento de Baccharis longiattenuata e atributos de densidade de galhas e organismos galhadores nas restingas arbustiva (Ra) e arbustivo-arbórea (Raa) do Parque Estadual Acaraí, São Francisco do Sul, SC. Os números em negrito representam diferenças estatisticamente significantes pelo teste t de Student $(\alpha=0.5)$.

Table 1 - Mean and respective standard deviations ( \pm ) of leaf and growth characteristics of Baccharis longiattenuata and gall density and galling density attributes in shrub (Ra) and shrub (Raa) restingas of Acaraí State Park, São Francisco do Sul, SC. The numbers in bold represent statistically significant differences by the Student t test $(\alpha=0.5)$.

\begin{tabular}{|c|c|c|c|}
\hline & \multirow{2}{*}{ Atributos } & \multicolumn{2}{|c|}{ Formações vegetais } \\
\hline & & $\mathbf{R a}$ & Raa \\
\hline \multirow{9}{*}{ Vigor da planta } & Altura da planta (m) & $1,72 \pm 32,93$ & $3,51 \pm 93,50$ \\
\hline & $\mathrm{DAP}(\mathrm{cm})$ & $5,63 \pm 1,55$ & $9,83 \pm 2,45$ \\
\hline & Área da copa $\left(\mathrm{cm}^{2}\right)$ & $10,93 \pm 4,84$ & $12.36 \pm 10,10$ \\
\hline & Volume da planta $\left(\mathrm{cm}^{3}\right)$ & $1621,46 \pm 1238,54$ & $10772,43 \pm 7337,94$ \\
\hline & Comprimento do ramo $(\mathrm{cm})$ & $10,93 \pm 3,23$ & $11,74 \pm 4,46$ \\
\hline & $\mathrm{N}^{\circ}$. de folhas apicais & $11,84 \pm 4,16$ & $11,72 \pm 3,86$ \\
\hline & Teor de nitrogênio foliar $\left(\mathrm{g} \cdot \mathrm{kg}^{-1}\right)$ & $16,67 \pm 1,24$ & $17,24 \pm 1,18$ \\
\hline & $\operatorname{AEF}\left(\mathrm{cm}^{2} \cdot \mathrm{g}^{-1}\right)$ & $85,25 \pm 14,87$ & $102,79 \pm 26,60$ \\
\hline & Peso seco foliar (g) & $0,02 \pm 0,001$ & $0,01 \pm 0,003$ \\
\hline \multirow{10}{*}{$\begin{array}{l}\text { Atributos foliares e } \\
\text { densidade de galhas }\end{array}$} & Área foliar $\left(\mathrm{cm}^{2}\right)$ & $1,79 \pm 0,47$ & $1,99 \pm 0,58$ \\
\hline & $\mathrm{N}^{\circ}$. de folhas apicais com galhas & $2,78 \pm 2,72$ & $3,02 \pm 2,50$ \\
\hline & $\mathrm{N}^{\circ}$. total de folhas no ramo & $14,04 \pm 5,54$ & $14,96 \pm 4,98$ \\
\hline & $\mathrm{N}^{\circ}$. de folhas com galhas & $3,64 \pm 3,04$ & $4,50 \pm 3,27$ \\
\hline & Folhas com galhas (\%) & 26 & 30 \\
\hline & Área foliar com galha $\left(\mathrm{cm}^{2}\right)$ & $0,19 \pm 0,15$ & $0,32 \pm 0,18$ \\
\hline & $\mathrm{N}^{\circ}$. absoluto de galhas por folha & $2,97 \pm 2,63$ & $4,33 \pm 5,17$ \\
\hline & $\mathrm{N}^{\circ}$. de galhas / $\mathrm{N}^{\circ}$. de folhas apicais & $0,98 \pm 1,16$ & $1,95 \pm 2,66$ \\
\hline & Área da galha $\left(\mathrm{mm}^{2}\right)$ & $1,46 \pm 0,45$ & $1,58 \pm 0,67$ \\
\hline & $\mathrm{N}^{\circ}$. de ácaros por galha & $106,96 \pm 104,69$ & $62,26 \pm 46,51$ \\
\hline
\end{tabular}

(CTC) apresentados. As maiores diferenças observadas foram a saturação por bases (V), que foi maior em restinga arbustiva, e umidade gravimétrica, maior em restinga arbustivoarbórea. $\mathrm{O}$ fósforo $(\mathrm{P})$, cálcio $(\mathrm{Ca})$, magnésio $(\mathrm{Mg})$, sódio $(\mathrm{Na})$, soma de bases $(\mathrm{SB})$ e CTC apresentaram uma menor variação entre os locais estudados, porém levemente superior em restinga arbustiva. A espessura de serapilheira e teor de potássio $(\mathrm{K})$ foram maiores em restinga arbustivoarbórea. Ambos os locais apresentaram solos ácidos, mas em Raa a acidez foi mais acentuada, representado pelo maior teor de $\mathrm{H}+\mathrm{Al}$ e menor valor do $\mathrm{pH}$. O teor de matéria orgânica (MO) no solo não diferiu entre as formações estudadas (Tab. 2). A radiação fotossinteticamente ativa (PAR) foi maior em restinga arbustiva, conforme o esperado (Tab. 2). 

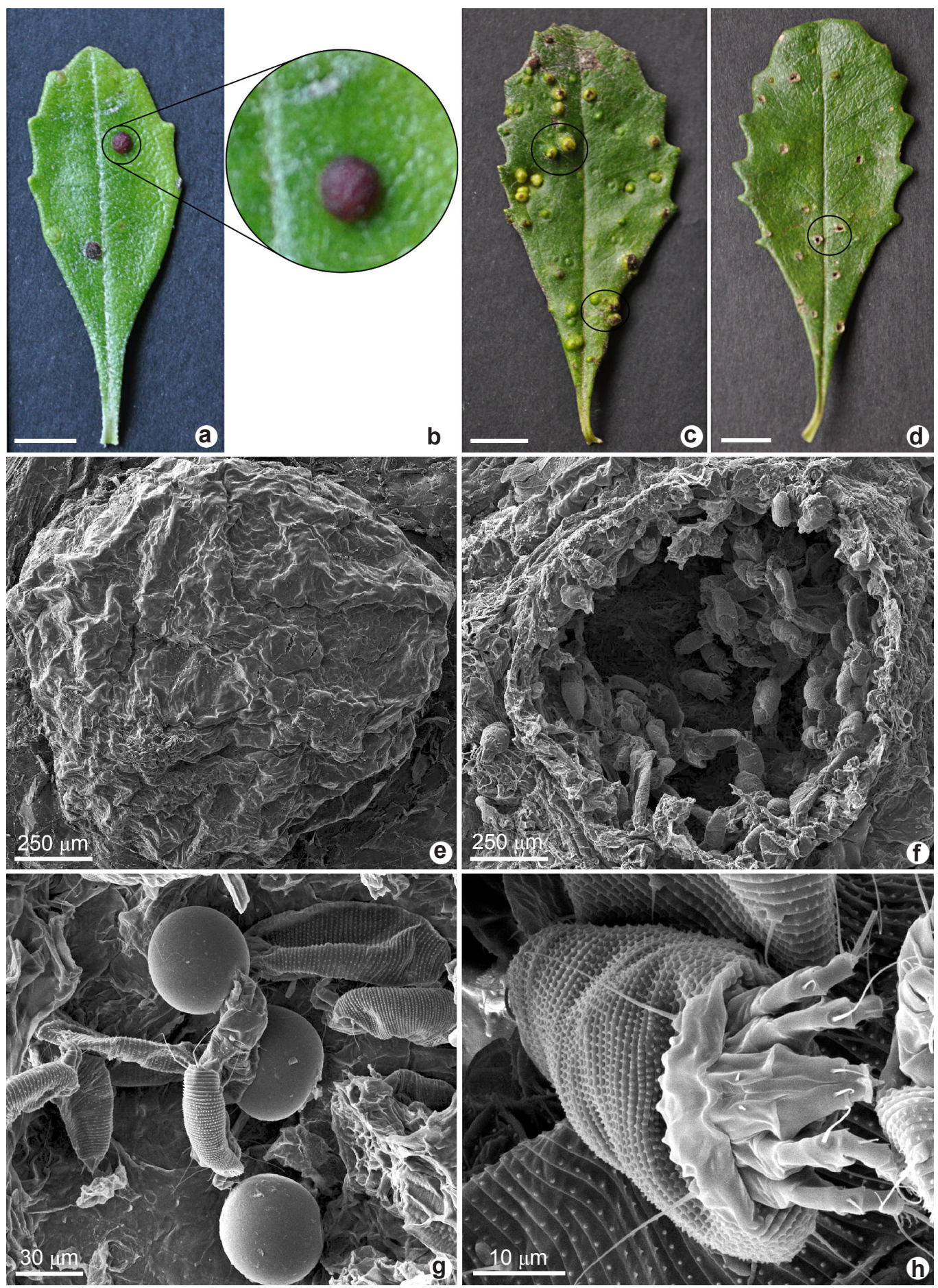

Figura 2 - Características morfológicas externa e interna da galha sobre a folha de $B$. longiattenuata evidenciando: a-b. coloração vermelha em galhas de estágio inicial de desenvolvimento; c. ocorrência de galhas em aglomerado; d. galhas abertas na face adaxial após a migração dos ácaros; e. vista frontal da galha; f. galha com corte transversal; g. ácaros e ovos dentro da galha; h. detalhe do ácaro galhador. Barras: a-d $=5 \mathrm{~mm}$.

Figure 2 - External and internal morphological characteristics of the gall leaf on B. longiattenuata leaf showing: a-b. red staining in early stage developmental galls; c. occurrence of galls in agglomerate; d. open galls on the adaxial side after migration of the mites; e. front view of the gall; f. gill with cross section; g. mites and eggs inside the gall; h. detail of the gall mite. Bars: a-d $=5 \mathrm{~mm}$. 
Tabela 2 - Valores médios dos atributos nutricionais do solo, salinidade $(n=10)$ e radiação fotossinteticamente ativa $(n=10)$ nas duas formações vegetais de restinga do Parque Estadual do Acaraí, São Francisco do Sul, SC. Legenda: restinga arbustiva $(\mathrm{Ra})$, restinga arbustivo-arbórea (Raa), $\mathrm{SB}=$ soma de bases, $\mathrm{CTC}=$ capacidade de troca catiônica, $\mathrm{V}=$ saturação por bases, $\mathrm{MO}=$ matéria orgânica, $\mathrm{PAR}=$ radiação fotossinteticamente ativa. Table 2 - Mean values of nutritional attributes of soil, salinity $(n=10)$ and photosynthetically active radiation $(n=10)$ in the two plant formations of restinga of the State Park of Acaraí, São Francisco do Sul, SC. Legend: shrub restinga (Ra), shrub-tree restinga $(\mathrm{Raa}), \mathrm{SB}=$ sum of bases, $\mathrm{CTC}=$ cation exchange capacity, $\mathrm{V}=$ base saturation, $\mathrm{MO}=$ organic matter, $\mathrm{PAR}=$ photosynthetically active radiation.

\begin{tabular}{|c|c|c|}
\hline \multirow{2}{*}{$\begin{array}{l}\text { Atributos } \\
\text { ambientais }\end{array}$} & \multicolumn{2}{|c|}{ Formações de restinga } \\
\hline & $\mathbf{R a}$ & Raa \\
\hline $\mathrm{pH}$ & 4,73 & 3,53 \\
\hline $\mathrm{P}\left(\mathrm{mg} / \mathrm{dm}^{3}\right)$ & 2 & 1 \\
\hline $\mathrm{K}\left(\mathrm{cmolc} / \mathrm{dm}^{3}\right)$ & 26,00 & 28,00 \\
\hline $\mathrm{Na}\left(\mathrm{mg} / \mathrm{dm}^{3}\right)$ & 0,8 & 0,7 \\
\hline $\mathrm{Ca}\left(\mathrm{cmolc} / \mathrm{dm}^{3}\right)$ & 1,03 & 0,56 \\
\hline $\operatorname{Mg}\left(\mathrm{cmolc} / \mathrm{dm}^{3}\right)$ & 0,4 & 0,2 \\
\hline $\mathrm{H}+\mathrm{Al}\left(\mathrm{cmolc} / \mathrm{dm}^{3}\right)$ & 1,5 & 2,16 \\
\hline $\mathrm{SB}\left(\mathrm{cmolc} / \mathrm{dm}^{3}\right)$ & 0,95 & 0,46 \\
\hline $\mathrm{CTC}\left(\mathrm{cmolc} / \mathrm{dm}^{3}\right)$ & 30,10 & 30,47 \\
\hline $\mathrm{V}(\%)$ & 38,61 & 29,81 \\
\hline $\mathrm{MO}\left(\mathrm{g} / \mathrm{dm}^{3}\right)$ & 14,00 & 14,17 \\
\hline $\begin{array}{l}\text { Umidade } \\
\text { gravimétrica (\%) }\end{array}$ & 7,0 & 12,0 \\
\hline Serapilheira (cm) & 2,4 & 3,7 \\
\hline $\operatorname{PAR}\left(\mu \mathrm{mol} \cdot \mathrm{s}^{-1} \cdot \mathrm{m}^{-2}\right)$ & $722,24 \pm 17,07$ & $524,44 \pm 19,52$ \\
\hline
\end{tabular}

\section{Discussão}

As características de solo e luminosidade de restinga apresentaram pequena variação entre os locais de estudo, sendo que a disponibilidade hídrica, $\mathrm{pH}$ do solo e intensidade luminosa apresentam diferenças mais acentuadas entre os locais de estudo. A quantidade de água no solo e luz incidente sobre os indivíduos estudados provavelmente influenciaram nos atributos foliares e arquiteturais da planta, e possivelmente, influenciaram na dinâmica deste sistema galhador-hospedeiro.

A maior alocação de biomassa nos indivíduos de restinga arbustivo-arbórea, foi provavelmente em resposta a maior disponibilidade hídrica e quantidade de serapilheira acumulada sobre o solo, o que implica em constante oferta de água e ciclagem de nutrientes (Melo Jr. \& Boeger 2016; Todorovisky et al. 2015) e favorece o investimento da planta em crescimento a longo prazo. Aliado a isso, o incremento em altura pode ser uma estratégia para alcançar a luz (Almeida et al. 2005), tendo em vista que na formação arbustivo-arbórea há maior sobreposição das copas entre as árvores vizinhas aumentando o nível de sombreamento (Melo Jr. \& Boeger 2015).

Os atributos de vigor geral da planta apresentam relação direta com número absoluto de galhas entre as populações de $B$. longiattenuata, evidenciada pelas análises de regressão. Tal relação pode ser explicada pelo fato de que hospedeiros maiores (com mais recursos) são mais facilmente encontrados e apresentam maior número de sítios meristemáticos, tornando-os bons hospedeiros para galhadores (Faria \& Fernandes 2001; Araújo et al. 2003; Espírito-Santo et al. 2007).

Plantas mais vigorosas (representadas por área da copa e número de folhas apicais), mais nutritivas (teor de nitrogênio) e com maior densidade de galhas na restinga arbustivo-arbórea corroboram a hipótese do vigor da planta, a qual prediz que módulos ou plantas mais vigorosas abrigam uma maior densidade de galhas (Price 1991). Tal hipótese tem sido evocada para explicar a densidade diferencial de galhas entre populações da mesma espécie em locais com distintas qualidades ambientais (Cornelissen et al. 2008). Entretanto, a correlação entre estes atributos foi fraca, o que permite inferir que outros fatores devem-se somar ao condicionamento desta dinâmica galhadorhospedeiro, ou, tal resultado pode ainda ter sido influenciado pelo baixo número amostral.

Embora as correlações entre atributos de vigor da planta e densidade de galhas tenham sido fracas, é importante ressaltar que a arquitetura geral da planta pode ter influência no padrão encontrado para densidade de galhas. As plantas da restinga arbustivo-arbórea apresentaram maior área de copa, volume e altura da planta. Todos estes atributos estão associado à plantas com maior número de sítios meristemáticos, e, portanto, maior número 
de tecidos reativos, tornando-os hospedeiros mais atrativos para os galhadores (Tuller et al. 2013; Espírito-Santo et al. 2007; Oliveira et al. 2013).

Apesar de diversos estudos apresentem a predominância de galhas em locais mais secos (Fernandes \& Price 1992; Ribeiro \& Basset 2007; Silva et al. 2016), o presente não apresenta evidências para tal conclusão, sendo, por outro lado, suporte para os resultados de Price \& Hunter (2015), que demonstraram que hospedeiros sob condições de maior precipitação e maior aporte hídrico no solo abrigam maior densidade de galhas se comparados à hospedeiros submetidos à seca severa, de modo que, nestes ocorre um declínio na densidade de galhas após o período de seca. Neste sentido, a escassez hídrica em restinga arbustiva, afeta indiretamente os galhadores, via redução de crescimento do hospedeiro.

Uma predição que tem sido corroborada na literatura, mas não neste estudo, é a correlação positiva entre esclerofilia e densidade de galhas (Fernandes \& Price 1991; Ribeiro \& Basset 2007; Ribeiro \& Basset 2016), evidenciando que fatores como escassez hídrica e nutricional no solo geram um efeito cascata sobre os galhadores. A Hipótese do Estresse Ambiental (Fernandes \& Price 1991) prediz que a folhas mais esclerofilas suportam uma densidade de galhas, pois apresentam características que conferem vantagem para os galhadores em relação às folhas menos esclerófilas, como: i) maior longevidade foliar, garantindo o desenvolvimento completo da prole do galhador dentro da galha; ii) menor probabilidade de abscisão foliar; iii) alto conteúdo de compostos fenólicos, que é um composto importante na indução de galhas (Oliveira et al. 2016); iv) baixo valor nutricional para herbívoros de vida livre, reduzindo a possibilidade de predação dos galhadores.

Entretanto, B. longiattenuata apresentou folhas com altos valores de AEF (menos esclerófilas), um indicador de esclerofilia (PérezHarguindeguy et al. 2013), se comparada às outras espécies já estudadas nesta restinga, as quais foram mais esclerófilas (Todorovski et al. 2015; Bächtold \& Melo Jr. 2015; Silva et al. 2016; Liberato \& Melo Jr. 2016; Matilde-Silva \& Melo Jr. 2017). Além disso, a maior densidade de galhas foi observada em plantas de restinga arbustivo-arbórea, as quais apresentam uma maior AEF, ou seja, são folhas menos esclerófilas que em restinga arbustiva. Deste modo, a hipótese de que plantas esclerófilas suportam maior densidade de galhas não pôde ser corroborada por este estudo.
Por outro lado, o padrão encontrado de maior densidade de ácaros por galha em restinga arbustiva, pode estar relacionado à maior esclerofilia desta população, visto que folhas esclerófilas (com menores valores de AEF) apresentam maior quantidade de tecido mecânico e são mais longevas (Hanley et al. 2007), o que resulta em maior tempo de vida das galhas e, consequentemente, melhor suporte para um maior número de gerações de ácaros dentro da mesma galha.

As menores áreas foliares em $B$. longiattenuata de restinga arbustiva provavelmente ocorreram como estratégia de economia de água e controle da transpiração em resposta às altas incidências luminosa e de temperatura neste local (Boeger \& Gluzezak 2006; Melo Jr. \& Boeger 2016). Inversamente, o aumento das áreas foliares na restinga arbustivo-arbórea ocorreu em resposta ao sombreamento, para aumentar a área de captação de luz e maximizar a produção fotossintética, já que o aporte hídrico é favorável neste local (Melo Jr. \& Boeger 2016). Ambas as estratégias de economia/ maximização do aproveitamento de recursos atuam secundariamente como fatores subjacentes à maior ou menor densidade de galhas.

O nitrogênio é um componente de suma importância para biossíntese e funcionamento metabólico dos organismos (White 1984), de modo que plantas com altos teores de nitrogênio livre nos tecidos foliares sofrem maiores taxas de herbivoria por serem altamente nutritivas para os herbívoros. Diferentemente dos herbívoros de vida livre, no entanto, os galhadores apresentam a habilidade de alterar a síntese de compostos secundários, proteínas e tecidos vegetais em benefício próprio, tornando o tecido alterado, a galha propriamente dita, uma estrutura com tecidos nutritivos, independente da qualidade nutritiva do hospedeiro como um todo (Oliveira et al. 2016).

A indução da síntese de tecido nutritivo por galhadores foi demonstrada por Hartley (1998) que identificou uma maior disponibilidade de nitrogênio e água em tecidos foliares galhados se comparados aos tecidos não induzidos por galhadores. Deste modo, é evidente a importância do nitrogênio para o desenvolvimento do herbívoro, seja de vida livre, ou não, tais como galhadores e minadores.

Em B. longiattenuata de restinga os valores de teor de nitrogênio observados são altos para os padrões de florestas tropicais que se desenvolvem sobre espodossolos (Vitousek \& Sanford 1986; Britez et al. 1997; Boeger et al. 2005; Schlindwein et al. 2005). Este atributo, que representa a 
qualidade nutricional para herbívoros de vida livre, pode alterar a dinâmica galhador-planta indiretamente, por meio do aumento da capacidade fotossintética do hospedeiro, e consequente crescimento e produção de tecidos meristemáticos, visto que os teores de nitrogênio e de clorofila são positivamente relacionados (Heerdt \& Melo Jr. 2016).

A densidade de ácaros por galha em $B$. longiattenuata de restinga arbustiva assemelhase ao encontrado para Aceria doctersi sobre as folhas de Cinnamomum verum Presl. (Lauraceae) (Nasareen \& Ramani 2015) e Aceria latanae Cook (Acarina: Eriophyidae) em Lantana camara L. (Verbenaceae) (Moura et al. 2009). Sugerimos que a luz incidente sobre os indivíduos de $B$. longiattenuata de restinga arbustiva eleva a temperatura foliar e favorece o desempenho reprodutivo dos ácaros, como o demostrado por Nasareen \& Ramani (2014, 2015) em estudo com Aceria pongamiae (Keifer 1966) e Aceria doctersi (Nalepa 1909) (Acari: Eriophyidae).

Qualitativamente, as galhas não diferiram entre as populações de $B$. longiattenuata, mas foi observada uma correlação positiva entre área da galha e densidade de ácaros, evidenciando que o espaço pode ser um fator limitante para a população de ácaros dentro de cada galha.

Nos estágios iniciais do desenvolvimento, as galhas apresentaram coloração vermelha, possivelmente devido à produção de flavonoides que podem ter função de repelente químico contra herbívoros e predadores dos ácaros e funcionar como sinalizador que indica perigo ou recurso impalatável aos outros herbívoros, ou, podem atuar como proteção contra danos celulares causados por raios UV, uma vez que as plantas deste estudo estão submetidas à luz solar direta (Tattini et al. 2000; Lev-Yadun \& Gould 2009). Com o amadurecimento, as galhas assumem a cor da folha e tornam-se protegidas contra inimigos naturais pelo desenvolvimento de tecido esclerenquimático (Oliveira et al. 2016).

Finalmente, os fatores ambientais podem apresentar importante papel nos padrões observados de densidade de galhas e ácaros em $B$. longiatenuatta. Por exemplo, a típica incidência de ventos fortes associada à alta temperatura pode tornar este ambiente hostil para a locomoção e sobrevivência de ácaros ao ar livre que, devido ao seu tamanho diminuto, podem facilmente sofrer ressecamento levando-os à morte ou mesmo serem levados para longe do seu hospedeiro (Lindquist \&
Oldfield 1996). Portanto, pode existe uma maior vantagem adaptativa para a fêmea madura em permanecer e reproduzir na mesma galha do que migrar em busca de uma nova, o que resulta na alta densidade populacional de ácaros observada.

\section{Conclusão}

Este estudo evidenciou que as adaptações do hospedeiro ao ambiente de desenvolvimento podem alterar a dinâmica de colonização e desenvolvimento das populações de ácaros galhadores. Os dados suportam a Hipótese do Vigor da Planta para o sistema B. longiattenuataácaro no PEA e confirmam as hipóteses 1, 2 e 3. A hipótese 4 deste estudo foi refutada, indicando que o sucesso reprodutivo e a densidade populacional de ácaros podem estar relacionados à outros fatores como o número de sítios meristemáticos. Embora tenha sido observada uma relação de causa e efeito entre densidade de galhas e atributos de vigor da planta, a correlação foi fraca, sugerindo que outras características do hospedeiro e do ambiente devem estar moldando as relações ácaro-B. longiattenuata. Inferimos que a maior disponibilidade hídrica presente em restinga arbustivo-arbórea altera as taxas de crescimento de $B$. longiatenuatta em relação à restinga arbustiva, e indiretamente altera a dinâmica galhador-hospedeiro. A maior densidade populacional de ácaros pode ser decorrente da soma de diferentes fatores bióticos e abióticos, com destaque à AEF, a incidência de ventos e a alta temperatura em certas formações da restinga, sendo este último fator mais favorável ao sucesso reprodutivo dos ácaros. Nos indivíduos de restinga arbustiva os ácaros apresentaram maior densidade populacional, e, neste sentido, é possível inferir que, neste sistema, as características físicas foliares a frequência de ventos e a temperatura podem estar exercendo pressão sobre a distribuição dos ácaros galhadores em B. longiattenuata.

\section{Agradecimentos}

À CAPES, o apoio financeiro ao primeiro autor. Aos colegas do Laboratório de Anatomia e Ecologia Vegetal e a Rodrigo Oszika, a ajuda na obtenção de amostras em campo. A Gustavo Heiden (Embrapa), a determinação da espécie vegetal. Os autores agradecem ao Programa de Pesquisa em Biodiversidade - Bioma Mata Atlântica Centro Sul / SC (PPBioMA) o apoio. Este trabalho foi apoiado pela FAP / Univille através do processo 6055 do terceiro co-autor. 


\section{Referências}

Almeida ECS, Fagundes M \& Fernandes GW (2008) Influência das condições ambientais e do diametro da galha no sucesso de inseto galhador em Astronium fraxinifolium. Anais do XXII Congresso Brasileiro de Entomologia, Uberlândia.

Almeida SMZ, Soares AM, Castro EM, Vieira CV \& Gajego EB (2005) Alterações morfológicas e alocação de biomassa em plantas jovens de espécies florestais sob diferentes condições de sombreamento. Ciência Rural 35: 62-68.

Araújo AAA, Carneiro MAA \& Fernandes GW (2003) Efeitos do sexo, do vigor e do tamanho da planta hospedeira sobre a distribuição de insetos indutores de galhas em Baccharis pseudomyriocephala Teodoro (Asteraceae). Revista Brasileira de Entomologia 47: 483-490.

Arriola IA \& Melo Jr. JCF (2016) Richness of insect galls on shrub-tree restinga of a coastal plain of southern Brazil. Acta Biológica Catarinense 3: 121-37.

Arriola IA, Melo Jr. JCF \& Isaias RM (2015) Questioning the environmental stress hypothesis for gall diversity of restinga vegetation on dunes. Revista de Biología Tropical 63: 959-970.

Bächtold BA \& Melo Jr. JCF (2015) Plasticidade morfológica de Calophyllum brasiliense Camb. (Calophyllaceae) em duas formações de restinga no sul do Brasil. Acta Biológica Catarinense 2: 21-32.

Boeger MRT \& Gluzezak RM (2006) Adaptações estruturais de sete espécies de plantas para as condições ambientais da área de dunas de Santa Catarina, Brasil. Iheringia 61: 73-82.

Boeger MRT, Wisniewski C \& Reissmann CB (2005) Nutrientes foliares de espécies arbóreas de três estádios sucessionais de floresta ombrófila densa no sul do Brasil. Acta Botanica Brasilica 19: 167-181.

Borcard D, Gillet F \& Legendre P (2011) Numerical ecology with R. Springer, New York. 319p.

Bregonci JM, Polycarpo PV \& Maia VC (2010) Galhas de insetos do Parque Estadual Paulo César Vinha (Guarapari, ES, Brasil). Biota Neotropica 10: 265-274.

Britez RM, Reissmann CB, Silva SM, Athayde SF, Lima RXB \& De Quadros RM (1997) Chemical characterization of two forests on the coastal plains of the Ilha do Mel, Paraná, Brazil. Developments in Plants and Soil Sciences 78: 461-462.

Cornelissen TG, Fernandes GW \& Vasconcellos-Neto J (2008) Size does matter: Variation in herbivory between and within plants and the plant vigor hypothesis. Oikos, Kopenhagen 117: 1121-1130.

Costa FV, Fagundes M \& Neves FS (2010) Arquitetura da planta e diversidade de galhas associadas à Copaifera langsdorffii (Fabaceae). Ecologia Austral 20: 9-17.

Crawley MJ (2007) The R book. John Wiley \& Sons, Chichester. 951p.
Damasceno MRA (2008) Ácaros associados a espécies vegetais cultivados na região semi-árida de Minas Gerais, Brasil. Dissertação de Mestrado. Universidade Estadual de Montes Claros, Janaúba. $143 f$.

EMBRAPA (2013) Sistema brasileiro de classificação de solos. $3^{\mathrm{a}}$ ed. EMBRAPA, Brasília. 283p.

Espírito-Santo MM, Neves FS, Andrade-Neto FR \& Fernandes GW (2007) Plant architecture and meristem dynamics as the mechanisms determining the diversity of gall-inducing insects. Oecologia, 153: 353-364.

Fagundes M \& Gonçalves CL (2005) Ataque de um inseto galhador (Diptera: Cecidomyiidae) em Astronium fraxinifolium (Anacardiaceae) em uma floresta estacional. Unimontes Científica 7: 107-114.

Faria ML \& Fernandes GW (2001) Vigour of a dioecious shrub and attack by a galling herbivore. Ecological Entomology 26: 37-45.

FATMA - Fundação do Meio Ambiente (2008) Plano de manejo do Parque Estadual do Acaraí. FATMA, Curitiba. 157p.

Fernandes GW \& Price PW (1991) Comparisons of tropical and tempera te galling species richness: the roles of environmental harshness and plant nutrient status. In: Price PW, Lewinsohn TM, Fernandes GW \& Benson WW (eds.) Plant-animal interactions: evolutionary ecology in tropical and temperate regions. Wiley, New York. Pp. 91-115.

Fernandes GW \& Price PW (1992) The adaptative significance of insect gall distribution: survivorship of species in xeric and mesic habitats. Oecologia 90: 14-20.

Gonçalves-Alvim SJ, Faria ML\& Fernandes GW (1999) Relationships between four neotropical species of galling insects and shoot vigor. Anais da Sociedade Entomológica do Brasil 28: 147-155.

Guedes JVC, Navia D, Lofego AC \& Dequech STB (2007) Ácaros associados à cultura da soja no Rio Grande do Sul, Brasil. Neotropical Entomology 36: 288-293.

Hanley ME, Lamont BB, Fairbanks MH \& Rafferty CM (2007) Plant structural traits and their role in antiherbivore defence. Perspectives in Plant Ecology, Evolution and Systematics 4: 157-178.

Hartley SE (1998) The chemical composition of plant galls: are levels of nutrients and secondary compounds controlled by the gall-former? Oecologia 113: 492-501

Heerdt ST \& Melo Jr. JCF (2016) Estratégias de defesa e nível de herbivoria entre estratos da copa de Inga edulis Mart. (Fabaceae) em ambiente florestal. Acta Biologica Venezuelanica 39: 101-117.

Heiden G \& Schneider A (2015) Baccharis. In: Lista de espécies da flora do Brasil. Jardim Botânico do Rio de Janeiro. Disponível em <http://floradobrasil.jbrj. 
gov.br/jabot/floradobrasil/FB104346>. Acesso em 10 outubro 2017.

Isaias RMS, Carneiro RGS, Oliveira DC \& Santos JC (2013) Illustrated and annotated checklist of Brazilian gall morphotypes. Neotrop Entomol 42: 230-239.

Julião GR, Venticinque EM, Fenandes GW \& Price PW (2014) Unexpected high diversity of galling insects in the Amazonian upper canopy: the savanna out there. PLoS ONE 9: e114986.

Keifer HH, Baker EW, Kono T, Delfinado M \& Styer WE. (1982) An illustrated guide to plant abnormalities caused by eriophyid mites in North America. Agricultural Research Service, United States Department of Agriculture, Washington, DC. 178p.

Kraus JE \& Arduin M (1997) Manual básico de métodos em morfologia vegetal. Editora Universidade Rural, Seropédica. 194p.

Liberato IS \& Melo Jr. JCF (2016) Morphological plasticity of Ilex theezans Mart. ex Reissek (Aquifoliaceae) in two restinga vegetation of Santa Catarina coastal plain. Acta Biológica Catarinense 3: 91-101.

Lev-Yadun S \& Gould KS (2009) Role of anthocyanins in plant defense. In: Gould K, Davies KM \& Winefield C (eds.) Anthocyanins. Springer Verlag, New York. Pp. 22-48.

Lindquist EE \& Oldfield GN (1996). Evolution of eriophyoid mites in relation to their host plants. In: Lindquist EE, Sabelis MW \& Bruin J (eds.) Eriophyoid mites - Their biology, natural enemies and control. Elsevier Science Publisher, Amsterdam. Pp. 277-300.

Maia VC (2013) Insect galls from restingas of Southeastern Brazil, with new records. Biota Neotropica 13: 194-209.

Mani M (1964) Ecology of plant galls. W. Junk, The Hague. 434p.

Matilde-Silva M \& Melo Jr. JCF (2017) Plasticidade da folha e lenho de cinco espécies lenhosas em duas áreas de restinga no Sul do Brasil. Iheringia, Série Botânica 72: 173-180,

Melo Jr. JCF \& Boeger MRT (2015) Riqueza, estrutura e interações edáficas em um gradiente de restinga do Parque Estadual do Acaraí, estado de Santa Catarina, Brasil. Hoehnea 42: 207-232.

Melo Jr. JCF \& Boeger MRT (2016) Leaf traits and plastic potential of plant species in a light-edaphic gradient from restinga in southern Brazil. Acta Biológica Colombiana 21: 51-62.

Mendonça, I. (2009). Estudo das interações plantaherbívoro em Laguncularia racemosa (L.) C.F. Gaertn. (Combretaceae) no manguezal de Maracaípe, Ipojuca, Pernambuco, Brasil. Revista de Biologia Neotropical 5: 73-74.
Moraes GJ \& Flechtmann CHW (1981) Ácaros fitófagos do Nordeste do Brasil. Pesquisa Agropecuária Brasileira 16: 177-186.

Moura MZD, Soares GLG \& Isaias RMS (2009) Ontogênese da folha e das galhas induzidas por Aceria lantanae Cook (Acarina:Eriophyidae) em Lantana camara L. (Verbenaceae). Revista Brasileira de Botânica 32: 271-282.

Nasareen PMN \& Ramani N (2014) Seasonal variation in the population density of the gall mite, Aceria pongamiae Keifer 1966 (Acari: Eriophyidae) within the leaf galls of Pongamia pinnata (L.). Journal of Entomology and Zoology Studies 2: 126-130.

Nasareen PMN \& Ramani N (2015) Seasonal variation in the population density of the gall mite, Aceria doctersi (Nalepa, 1909) (Acari :Eriophyidae) within the leaf galls of Cinnamomum verum (Presl.). International Journal of Science and Research 3: 126-130.

Nelson DW \& Sommers LE (1996) Total carbon, organic carbon and organic matter. In: Page AL, Miller RH \& Keeney DR (eds.) Methods of soil analysis. Part 3. Chemical Methods-SSSA Book Series no 5 . Soil Sciense Society of America and American Society of Agronomy, Madison. Pp. 963-1010.

Oliveira DC, Mendonça Júnior MS, Moreira ASFP, Lemos-Filho JP \& Isaias RMS (2013) Water stress and phenological synchronism between Copaifera langsdorffii (Fabaceae) and multiple galling insects: formation of seasonal patterns. Journal of Plant Interactions 8: 225-233.

Oliveira DC, Isaias RMS, Fenandes GW, Ferreira BG, Carneiro RGS \& Furazo L (2016) Manipulation of host plant cells and tissues by gall-inducing insects and adaptive strategies used by different feeding guilds. Journal of Insect Physiology 84: 103-113.

Oliveira JAB \& Cortez JSA (2015) Herbivoria em Dalbergia ecastophyllm na restinga de Pernambuco. Natureza on line 4: 151-154.

Pérez-Harguindeguy N, Díaz S, Garnier E, Lavorel S, Poorter H, Jaureguiberry P, Bret-Harte MS, Cornwell WK, Craine JM, Gurvich DE, Urcelay C, Veneklaas EJ, Reich PB, Poorter L, Wright IJ, Ray P, Enrico L, Pausas JG, de Vos AC, Buchmann N, Funes G, Quétier F, Hodgson JG, Thompson K, Morgan HD, Steege H, van der Heijden MGA, Sack L, Blonder B, Poschlod P, Vaieretti MV, Conti G, Staver AC, Aquino S \& Cornelissen JHC (2013) New handbook for standardized measurement of plant functional traits worldwide. Australian Journal of Botany 61: 167-234.

Price PW, Fernandes GW \& Waring GL (1987) Adaptative nature of galls. Environmental Entomology 16: 1524.

Price PW (1991) The plant vigor hypothesis and herbivore attack. Oikos 62: 244-251. 
Price PW \& Hunter MD (2015) Population dynamics of an insect herbivore over 32 years are driven by precipitation and host-plant effects: testing model predictions. Environmental Entomology Advances 44: 463-473.

Ribeiro SP \& Basset Y (2007) Gall-forming and freefeeding herbivory along vertical gradients in a lowland tropical rainforest: the importance of leaf sclerophylly. Ecography 30: 663-672.

Ribeiro SP \& Basset Y (2016) Effects of sclerophylly and host choice on gall densities and herbivory distribution in an Australian subtropical forest. Austral Ecology 41: 219-226.

Scarano FR (2002) Structure, function and floristic relationships of plant communities in stressful habitats marginal to the Brazilian Atlantic rainforest. Annals of Botany 90: 517-524.

Schlindwein CCD, Fett-Neto AG \& Dillenburg LR (2005) Chemical and mechanical changes during leaf expansion of four woody species of a dry restinga woodland. Plant Biology 8: 430-438

Silva KR, Melo Júnior JCF \& Boeger MRT (2016) Variações fenotípicas em Andira fraxinifolia Benth. (Fabaceae) em duas fitofisionomias de Restinga. Hoehnea 43: 229-237.

Tattini M, Gravano E, Pineli P, Mulinacci N \& Romani A (2000) Flavonoids accumulate in leaves and glandular trichomes of Phillyrea latifolia exposed to excess solar radiation. New Phytologist 148: 69-77.
Tedesco MJ, Gianello C, Bissani CA, Bohnen H \& Volkweiss SJ (1995) Análise de solo, plantas e outros materiais. Boletim Técnico 5. $2^{\text {a }}$ ed. Universidade Federal do Rio Grande do Sul, Porto Alegre. 147p.

Todorovski ECD, Melo Jr. JCF, Amorim MW \& MatildeSilva M (2015) Potencial plástico de Nectandra oppositifolia Nees. (Lauraceae) em fisionomias de floresta ombrófila densa e restinga. Natureza on line 13: 70-76.

Tuller J, Queiroz ACM, Luz GR \& Silva JR (2013) Gall-forming insect attack patterns: a test of the plant vigor and resource consentration hypotheses. Biotemas 26: 45-51.

Vendramini F, Díaz S, Gurvich DE, Wilson PJ, Thompson K \& Hodgson JG (2002) Leaf traits as indicators of resource-use strategy in floras with succulent species. New Phytologist 154: 147-157.

Vitousek PM \& Sanford Jr. RL (1986) Nutrient cycling in moist tropical forest. Annual Review of Ecology and Systematics 17: 137-167.

White TC (1969) An index to measure weather-induced stress of trees associated with outbreaks of psyllids in Australia. Ecology 50: 905-999.

White TCR (1984) The abundance of invertebrate herbivores in relation to the availability of nitrogen in stressed food plants. Oecologia 63: 90-105.

Williams MA \& Cronin JT (2004) Response of a Gall-forming guild (Hymenoptera: Cynipidae) to stressed and vigorous prairie roses. Environmental Entomology 33: 1052-1061. 